\title{
Freiligrath, Ferdinand
}

3046 Eberhardt, Joachim: Über die Quelle des Freiligrath-Epithetons »Trompeter der Revolution«. In: GrabbeJb. 30/31. 2011/2012. S. 207-212.

3047 Füllner, Bernd; Nühlen, Kathrin: »Stickluft oben u. Stickluft unten - was soll aus dieser Misere Gutes kommen?« Freiligraths Briefe an Levin Schücking aus dem Jahr 1843. In: GrabbeJb. 30/31. 2011/2012. S. 166-206; Ill.

3048 Hellfaier, Detlev: Von Freunden, Witwen und schönen Kindern. Neue Quellen für die Freiligrath-Forschung. In: GrabbeJb. 30/31. 2011/2012. S. 146-165.

$\rightarrow \quad 3004$

Freytag, Gustav

3049 Estermann, Monika: Gustav Freytag und das Sammeln im Historismus. In: AGB. Nr. 67. 2012. S. 169-181; Ill.

3050 Keppler-Tasaki, Stefan: Britische Bilder aus der deutschen Vergangenheit. Gustav Freytags Die Ahnen und der Maßstab Walter Scotts. In: $\langle 2510\rangle$ S. 185-209.

3051 Schneider, Lothar L.: Reisen vor Ort. Zur multiplen Verwendung von Reiseliteratur in Gustav Freytags Soll und Haben. In: 〈3010〉 S. 157-174.

$\rightarrow \quad 2406$

Gerstäcker, Friedrich $\rightarrow 3005$

Glaßbrenner, Adolf $\rightarrow 3724$

Goltz, Bogumil

3052 Grotek, Edyta: Der deutsche Genius im Spiegel seiner Sprache - das Selbstbild der in Thorn des 19. Jahrhunderts wohnhaften Deutschen. Versuch einer Analyse anhand »Die Deutschen« von Bogumil Goltz. In: $\langle 2431\rangle$ S. 67-79.

\section{Gotthelf, Jeremias}

3053 Gotthelf, Jeremias: Historisch-kritische Gesamtausgabe. Hrsg. von Barbara Mahlmann-Bauer, Christian von Zimmermann. - Hildesheim [u. a.]: Olms

Abteilung D. Neuer Berner-Kalender.

1. Drucktext, Spätere Bearbeitungen, Handschriftliche Texte. Hrsg. von Christian von Zimmermann . . . 2012. 870 S. ISBN 978-3-487-14576-1: $€ 228.00$ 
3. Kommentar. Teilbd. 1. Hrsg. von Christian von Zimmermann in Zusammenarbeit mit Barbara Berger Guigon . . . 2012. 652 S., Ill. ISBN 978-3-487-14828-1: € 198.00

3. Kommentar. Teilbd. 2. Hrsg. von Christian von Zimmermann in $\mathrm{Zu}$ sammenarbeit mit Barbara Berger Guigon . . . 2012. S. 655-1476, Ill., 1 CD-ROM ISBN 978-3-487-14829-8: $€ 198.00$

Abteilung F. Politische und pädagogische Publizistik.

1. Politische Publizistik 1828-1854. Teil 1. Text. Hrsg. von Barbara Mahlmann-Bauer . . . 2012. 405 S., Ill. ISBN 978-3-487-14607-2: € 148.00

1. Politische Publizistik 1828-1854. Teil 2. Kommentar. Hrsg. von Barbara Mahlmann-Bauer .. . 2012. 786 S., Ill. ISBN 978-3-487-14608-9: $€ 198.00$

Darüber, dass die von R. Hunziker, H. Bloesch, K. Guggisberg und W. Juker besorgte Edition von Jeremias Gotthelfs Sämtlichen Werken (1911-1977) wissenschaftlichen Anforderungen nicht zu genügen vermag, besteht in der germanistischen Forschung Konsens, und so ist es außerordentlich $\mathrm{zu}$ begrüßen, dass endlich auch der letzte Autor in der Trias der bedeutendsten Schweizer Dichter des 19. Jh. mit einer auf 67 Bde. ausgelegten hist.-krit. Gesamtausg. seiner Schriften gewürdigt wird. Die ebenso mutige wie plausibel begründete Entscheidung der Hrsg., den Neuen Berner Kalender (1840-45), G.s politische und pädagogische Publizistik sowie dessen Predigten an den Beginn ihres ambitionierten Vorhabens zu stellen, überzeugt, bilden diese doch den diskursiven Rahmen, in den sich die Romane und Novellen G.s einfügen. Die nun vorl. ersten Bde. machen deutlich, dass den Lesern nicht nur eine höchsten editionsphilologischen Ansprüchen genügende Wiedergabe, sondern außerdem eine historisch umfassende Kontextualisierung des G.'schen Euvres geboten werden soll. Durch kenntnisreiche Einführungen in die einzelnen Werkkomplexe, profunde Analysen und materialreiche Erläuterungen werden die samt einem Variantenapparat abgedruckten, wo sinnvoll durch Transkriptionen alternativer Fassungen oder - wie im Fall des reich bebilderten Neuen Berner Kalenders- Faksimiles sowie den Abdruck der im Nachlass befindlichen handschriftlichen Notizen und Entwürfe ergänzten Texte in transparent gegliederter Form zugänglich gemacht und umsichtig gedeutet. Dabei leisten die Hrsg. wertvolle Grundlagenforschung und bereiten den Boden für eine erneute Beschäftigung mit einem Schriftsteller, der bei aller Exzeptionalität insofern zeittypisch erscheint, als nicht nur sein publizistisches, sondern auch sein poetisches Wirken konsequent die politischen, sozialen, ökonomischen, religiösen und intellektuellen Umbrüche seiner Epoche spiegelt. Dies durch sorgfältige Arbeit am Text zu beweisen, gehört zu den großen Verdiensten eines Editionsprojekts, das zweifelsfrei neue Maßstäbe in der Erschließung literarischer Überlieferung setzt.

Silvia Serena Tschopp, Augsburg 